\title{
Fine Structure of Methane and Other Hydrocarbon-utilizing Bacteria
}

\author{
By STEPHANIE L. DAVIES AND R. WHITTENBURY \\ Department of General Microbiology, University of Edinburgh, \\ College of Agriculture, West Mains Road, Edinburgh EH $9{ }_{3} J G$
}

(Accepted for publication I6 January 1970)

\begin{abstract}
SUMMARY
Methane-utilizing bacteria were examined by electron microscopy and found to possess complex membranous structures within the cytoplasm. Two types of membrane organization were recognized. One type consisted of pairs of membranes which either extended throughout the organism or were arranged at the periphery where they ran parallel to the cytoplasmic membrane. The other type consisted of vesicular discs of membrane organized into bundles which were distributed throughout the organism. Bacteria utilizing $\mathrm{C}_{2}$ to $\mathrm{C}_{4}$ gaseous $n$-alkanes and $\mathrm{C}_{11}$ to $\mathrm{C}_{18}$ liquid $n$-alkane mixture did not possess such extensive membranous structures. The former contained membranous bodies of the mesosome type, whilst the latter possessed only a cytoplasmic membrane. These structural differences add to the growing list of properties separating $\mathrm{CH}_{4}$-utilizing bacteria from those utilizing $\mathrm{C}_{2}$ and higher $n$-alkanes.
\end{abstract}

\section{INTRODUCTION}

Complex internal membrane systems, in contrast to the relatively simple intracytoplasmic bodies classified as mesosomes, are restricted in the bacteria to a few groups such as the photosynthetic bacteria (Pfennig, 1967) and the nitrifying bacteria (Murray \& Watson, 1965; S. W. Watson, private communication). Their presence in methane-utilizing bacteria, briefly described by Whittenbury (1969) and later by Proctor, Norris \& Ribbons (1969), seems to be the first instance of such complex systems in obligate heterotrophs. These membrane systems are described in more detail in this paper and are compared with the type of internal organization found in bacteria utilizing higher hydrocarbons.

\section{METHODS}

Organisms and culture. The methane-utilizing bacteria studied, and the methods and inorganic media used, were those described by Whittenbury, Phillips \& Wilkinson (1970). Strains of the Mycobacterium-Corynebacterium complex utilizing gaseous hydrocarbons, and Gram-negative cocci utilizing liquid $n$-alkanes were isolated in this laboratory by $\mathrm{Mr}$ A. G. McLee. They were cultured on the inorganic medium used for methane utilizers in an atmosphere of air and gaseous $n$-alkanes $\left(C_{2}, C_{3}\right.$ or $\left.C_{4}\right)$, and in an atmosphere of air and vapour given off from filter paper impregnated with a $\mathrm{C}_{11}$ to $\mathrm{C}_{18} n$-alkane mixture, respectively. All cultures were grown at $30^{\circ}$ and the organisms harvested after 2 days.

Electron microscopy. The bacteria were fixed and embedded following the procedure 
described by Bradley \& Dewar (I967). After fixation in $6.25 \%(w / v)$ glutaraldehyde and then in $\mathrm{I} \%(\mathrm{w} / \mathrm{v})$ osmic acid the procedure was modified by suspending the bacteria in $2.0 \%(\mathrm{w} / \mathrm{v})$ agar. Some of the suspension was transferred to the fine tube of a Pasteur pipette, allowed to solidify and then extruded. Small blocks, about I mm. long, were cut from the agar and dehydrated in acetone. Staining with uranyl acetate was carried out in the initial stages of dehydration. The agar blocks were finally embedded in 'Vestopal'. Thin sections were cut with a diamond knife on a Huxley microtome and mounted on grids. The sections were stained with lead citrate for 2 min. (Reynolds, 1963) before examination in the electron microscope.

For negative staining, harvested bacteria were washed in $0 . \mathrm{I} M$ ammonium acetate solution containing sucrose, $0.2 \%(\mathrm{w} / \mathrm{v})$, and centrifuged. They were resuspended in ammonium acetate-sucrose solution and a drop was mixed with a drop of neutral potassium phosphotungstate, $2 \%(w / v)$. A thin film of this mixture was allowed to dry on a carbon-coated grid.

\section{RESULTS AND DISCUSSION}

Representative strains of five groups, 'Methylosinus', 'Methylocystis', 'Methylomonas', 'Methylococcus' and 'Methylobacter' (Whittenbury et al. 1970), were found to possess complex internal membranous structures. Two patterns of organization were recognized, type I being found in the rod-coccoid organisms ('Methylomonas', 'Methylococcus' and 'Methylobacter' groups) and type II in the vibrioid organisms ('Methylosinus' and 'Methylocystis' groups).

Type I. Organisms in this category possessed structures resembling those in Pl. I, fig. I, 2. The membranes, cut across in these sections, were aggregated into bundles, which were a constant feature of these bacteria when grown on either methane or methanol. The individual membranes, which were about $90 \AA$ thick, consisted of two outer electron-dense layers and an inner electron-transparent layer, and were similar in size and appearance to the cytoplasmic membrane. The parallel close-packing of the membranes within a bundle gave rise to triplet structures which were composed of pairs of adjacent membranes. The membrane units were in the form of flattened vesicles, the inner spaces of which usually contained material that appeared similar to the surrounding cytoplasm. The vesicular conformation of the membranes was seen more clearly in a fragment of a bacterium (Pl. I, fig. 3) where the breaking of the wall appeared to have released the membranes from their usual close-packed arrangement. The membrane vesicles were seen in a side-on position in bacteria where the plane of sectioning was parallel to the side walls of the vesicles (Pl. I, fig. 4). In such cases the membranes appeared as areas of relatively electron-dense material which were circular or ovoid in outline. Each bundle of membranes, therefore, appeared to consist of a number of disc-shaped vesicles in a highly oriented arrangement.

This interpretation was supported by negatively stained preparations of lysing bacteria. Although whole bacteria were not penetrated by the stain, the lysing organisms gave a three-dimensional impression of the numerous disc-shaped vesicles found within the bacteria (Pl. 2, fig. 5). This arrangement of vesicles bears a marked similarity to the smaller vesicular systems described in Rhodospirillum molischianum by Giesbrecht \& Drews (1962). In Pl. 2, fig. 6some of the closely-packed membranes are in an end-on position while others are in a side-on position. In fragments from disrupted bacteria, membrane discs tended to remain in groups accompanied by pieces of cytoplasmic 
membrane (Pl. 2, fig. 7). This arrangement of discs and cytoplasmic membrane fragments suggests that there might be an attachment between the internal and the cytoplasmic membranes. Invaginations of the cytoplasmic membrane (Pl. 2, fig. 8) and connexions between the membrane bundles and the cytoplasmic membrane (PI. 2, fig. 9) were seen in a number of sections, indicating that the membrane vesicles arose from invaginations of the cytoplasmic membrane.

Most strains contained bundles of uniformly graded vesicles, but some contained a variant type of bundle (Pl. 2, fig. 9) composed of irregularly sized vesicles.

Type II. The internal arrangement of membranes in organisms of this group, when grown on either methane or methanol, was more variable and less ordered than that of the rod-coccoid strains. The individual membranes, which were about $80 \AA$ thick and similar to the cytoplasmic membrane in both size and appearance, had the same three-layered structure as the type I membranes (Pl. 3, fig. IO). The membranes were always in pairs and bounded a lumen of varying dimensions which was usually filled with material noticeably less electron-dense than the surrounding cytoplasm.

In a few of the strains, paired membranes were usually found throughout the organism (Pl. 3, fig. II), although in some sections the membranes tended to be concentrated at the periphery (Pl. 3, fig. I2). The membrane system in these bacteria may have been in the form of tubes and irregularly shaped vesicles or of flattened, more lamella-like tubes. In the same strains the membranes occasionally appeared in a more regular, peripheral arrangement (Pl. 3, fig. 13, I4) and branching was sometimes apparent. In other strains the membranes were always found at the periphery, an arrangement that is similar to those described in Rhodopseudomonas palustris (Whittenbury \& McLee, 1967) and in Nitrobacter agilis and Nitrosomonas europaea (Murray \& Watson, 1965). In these methane utilizers the membrane system is probably in the form of a series of concentric vesicles which more or less completely enclose the inner part of the organism.

The three-dimensional structure of the two variants of the type II membrane system could not be confirmed with negatively stained preparations of glycerol-lysed cells (Eimhjellen, Steensland \& Traetteberg, 1967) as the membranous material appeared as a dense and convoluted mass.

\section{Higher hydrocarbon-utilizing bacteria}

Bacteria utilizing the $n$-alkanes, ethane, propane and butane, possessed membranous structures of the mesosome type. These were observed in thin sections and in negatively stained preparations of whole organisms. Each bacterium contained a number of convoluted membranous organelles of varying size (Pl. 4, fig. 15) with larger bodies occurring at sites of cross-wall formation (Pl. 4, fig. I6). Both types of mesosomes are very similar to those reported in Caulobacter crescentus (Cohen-Bazire, Kunisawa \& Poindexter, 1966). Some bacteria also contained an array of small convoluted structures around their periphery (Pl. 4, fig. 17) which were similar to those reported in Lactobacillus lactis (Hurst \& Stubbs, 1969). Bacteria growing on liquid $n$-alkanes contained no detectable membranes other than the cytoplasmic membrane (Pl. 4, fig. 18). 


\section{Discussion of the role of the membranous organelles}

The electron micrographs reveal a marked gradation in the complexity of membrane arrangement in the various groups of hydrocarbon-utilizing bacteria, with extensive membrane systems occurring only in the methane utilizers. The role of these extensive membrane systems has not yet been elucidated, but the probable significance of various functions can be assessed by comparison with other organisms.

Low solubility of the substrate and metabolic stress resulting from the synthesis of components from $\mathrm{C}_{1}$ compounds are unlikely to account for the development of such organelles. The higher hydrocarbon-utilizers have the same substrate solubility problem and yet do not differ greatly in structure from many heterotrophs growing in the presence of ample nutrients. The importance of these two functions in this context is further discounted by a consideration of the structure of Hydrogenomonas species. These organisms apparently possess only a cytoplasmic membrane (Schlegel, Gottschalk \& Von Bartha, I96I) and yet utilize $\mathrm{H}_{2}$, which has the same order of solubility as $\mathrm{CH}_{4}$, and, unlike the methane utilizers, Hydrogenomonas species also have to fix $\mathrm{CO}_{2}$ at the expense of reduced NAD and ATP. The unimportance of methane solubility in relation to membrane development also seems to be demonstrated by the behaviour of the organisms growing on methanol. Growth rates on methane and methanol were similar (Whittenbury et al. 1970) despite the fact that the concentration of methanol was sometimes 100 to $1000 \times$ greater than that of methane.

Evidence is beginning to accumulate (Patel, Hoare \& Taylor, 1969; Whittenbury et al. 1970) which suggests that methane oxidizers have physiological properties more in common with autotrophs than with heterotrophs and a comparison with organisms of similarly complex structure, such as the nitrifiers, may eventually provide an explanation of the significance of the extensive membrane systems. $\mathrm{CH}_{4}, \mathrm{NH}_{4}^{+}$and $\mathrm{NO}_{2}^{-}$appear to have thermochemical properties in common, in that electrons released in the oxidation of these compounds are likely to be at too high a potential to reduce NAD, and their subsequent oxidation at some later point in the electron transport chain would result in a low efficiency of coupling of phosphorylation to oxidation. Extensive membrane development in these organisms would therefore result in an increased capacity for respiratory activity with which to compensate for low phosphorylation efficiency. In this context an approximate estimation of the increase in membrane surface area per organism afforded by the internal membranes is of interest. In the rod-coccoid organisms with the type I membrane system a total of four bundles, each composed of 15 vesicles, has been calculated to be a conservative average per bacterium. Such an arrangement provides a surface area of about eight times that of the cytoplasmic membrane. The vibrioid organisms with the type II membranes in a peripheral arrangement contain, on average, two to three concentric vesicles per bacterium, resulting in a surface area of about four to six times that of the cytoplasmic membrane. Thus, although both membrane systems result in a considerable increase in the total membrane surface area per organism, there appears to be a marked difference between the two systems in the extent of that increase. A difference of a similar magnitude is found between the fastest generation times of the two groups of organisms, $3.5 \mathrm{hr}$ in the rod-coccoids and 5 to $6 \mathrm{hr}$ in the vibrioids (Whittenbury et al. 1970), implying that the growth rate is a function of membrane area. 
The authors are grateful to the Department of Zoology, University of Edinburgh, for providing the facilities for this work, and to Dr D. E. Bradley and his colleagues for their help and advice. This research was carried out while one of us (S. L. D.) was in receipt of a Science Research Council research fellowship, and was financed by a Science Research Council grant to Professor J. F. Wilkinson with whom we had helpful discussions.

\section{REFERENCES}

BRADLEy, D. E. \& DeWAR, C. A. (1967). Intracellular changes in cells of Escherichia coli infected with a filamentous bacteriophage. Journal of General Virology I, 179.

Cohen-Bazire, G., Kunisawa, R. \& PoIndeXter, J. S. (1966). The internal membranes of Caulobacter crescentus. Journal of General Microbiology 42, $30 \mathrm{I}$.

Eimhjellen, K. E., Steensland, H. \& TraetTeberG, J. (1967). A Thiococcus sp.nov.gen., its pigments and internal membrane system. Archiv für Mikrobiologie 59, 82.

GiesBRECHT,P. \& Drews, G.(1962). Elektronenmikroskopische Untersuchungen über die Entwicklung der 'Chromatophoren' von Rhodospirillum molischianum Giesberger. Archiv für Mikrobiologie 43, I52.

HURST, A. \& StUBBs, J. M. (1969). Electron microscopic study of membranes and walls of bacteria and changes occurring during growth initiation. Journal of Bacteriology 97, 1466.

MuRRaY, R. G. E. \& Watson, S. W. (1965). Structure of Nitrosocystis oceanus and comparison with Nitrosomonas and Nitrobacter. Journal of Bacteriology 89, I 594.

Patel, R., Hoare, D. S. \& TAYLOR, B. F. (1969). Biochemical basis for the obligate C-I dependence of Methylococcus capsulatus. Bacteriological Proceedings 128.

Pfennig, N. (1967). Photosynthetic bacteria. Annual Review of Microbiology 2I, 285.

Proctor, H. M., Norris, J. R. \& RibBons, D. W. (1969). Fine structure of methane-utilizing bacteria. Journal of Applied Bacteriology 32, I 18.

REYNolds, E. S. (1963). The use of lead citrate at high $\mathrm{pH}$ as an electron-opaque stain in electron microscopy. Journal of Cell Biology 17, 208.

Schlegel, H. G., GotTschalk, G. \& Von Bartha, R. (196I). Formation and utilization of poly- $\beta$ hydroxybutyric acid by knallgas bacteria (Hydrogenomonas). Nature, London I91, 463.

Whittenbury, R. (1969). Microbial utilization of methane. Process Biochemistry 4 (I), $5 \mathrm{I}$.

WhitTenbury, R. \& MCLeE, A. G. (1967). Rhodopseudomonas palustris and Rh. viridis-photosynthetic budding bacteria. Archiv für Mikrobiologie 59, 324.

Whittenbury, R., Phillips, K.C. \& Wilkinson, J. F. (1970). Enrichment, isolation and some properties of methane-utilizing bacteria. Journal of General Microbiology 6r, 205.

\section{EXPLANATION OF PLATES}

Plate I

Fig. I, 2. Sections of a 'Methylococcus' (subgroup 'minimus') strain showing the type I membrane system. The triplet structure of membrane pairs is apparent. $\times 80,000$.

Fig. 3. Fragment of a dividing 'Methylobacter' (subgroup 'vinelandii') strain showing the vesicular conformation of the membranes. $\times 60,000$.

Fig. 4. Section of a 'Methylococcus' (subgroup 'minimus') strain with two membrane bundles (M) in a side-on position. $\times 90,000$.

\section{Plate 2}

Fig. 5. Negatively stained preparation of a lysing 'Methylomonas'(subgroup ' rubrum') strain showing closely packed, disc-shaped membrane vesicles. $\times 50,000$.

Fig. 6. Negatively stained preparation of a lysing 'Methylomonas' (subgroup 'rubrum') strain showing membrane discs in end-on and side-on positions. $\times 50,000$.

Fig. 7. Negatively stained membrane discs and cytoplasmic membrane (arrowed) from a lysed 'Methylococcus' (subgroup 'minimus') strain.

Fig. 8. Section of a 'Methylomonas' (subgroup 'albus') strain showing invagination of the cytoplasmic membrane. $\times 100,000$. 
Fig. 9. Section of a 'Methylomonas' (subgroup 'BG $4 \mathrm{~A}$ ') strain with variant type of membrane bundle in section and side (M) view, and connexion (arrowed) between membrane bundle and cytoplasmic membrane. $\times 50,000$.

Plate 3

Fig. Io. Fragment of a 'Methylocystis' (subgroup 'parvus') strain showing the three-layered structure of the membranes. Arrows indicate bacterial wall. $\times 90,000$.

Fig. II. Section of a 'Methylosinus' (subgroup 'sporium') strain with the type II membrane system ramifying throughout the organism. $\times 60,000$.

Fig. 12. Section of a 'Methylosinus' (subgroup 'sporium') strain showing a concentration of the membranes towards the periphery of the organism. $\times 90,000$.

Fig. 13, 14. A more regular, peripheral arrangement of the membranes in a 'Methylosinus' (subgroup 'sporium') strain. The membrane system shows some branching (arrowed area). $\times 80,000$; 60,000 .

\section{Plate 4}

Fig. 15. Negatively stained preparation of a strain of the Mycobacterium-Corynebacterium complex grown on propane. Each bacterium contains numerous mesosomes. $\times 60,000$.

Fig. I6. Negatively stained, propane-utilizing bacterium of the Mycobacterium-Corynebacterium complex showing large mesosome at site of cross-wall formation. $\times 60,000$.

Fig. 17. Negatively stained, propane-utilizing bacterium of the Mycobacterium-Corynebacterium complex with peripheral membrane bodies. $\times 60,000$.

Fig. I8. Section of a Gram-negative coccal-rod grown on $C_{11}$ to $C_{18} n$-alkane mixture. $\times 75,000$. 

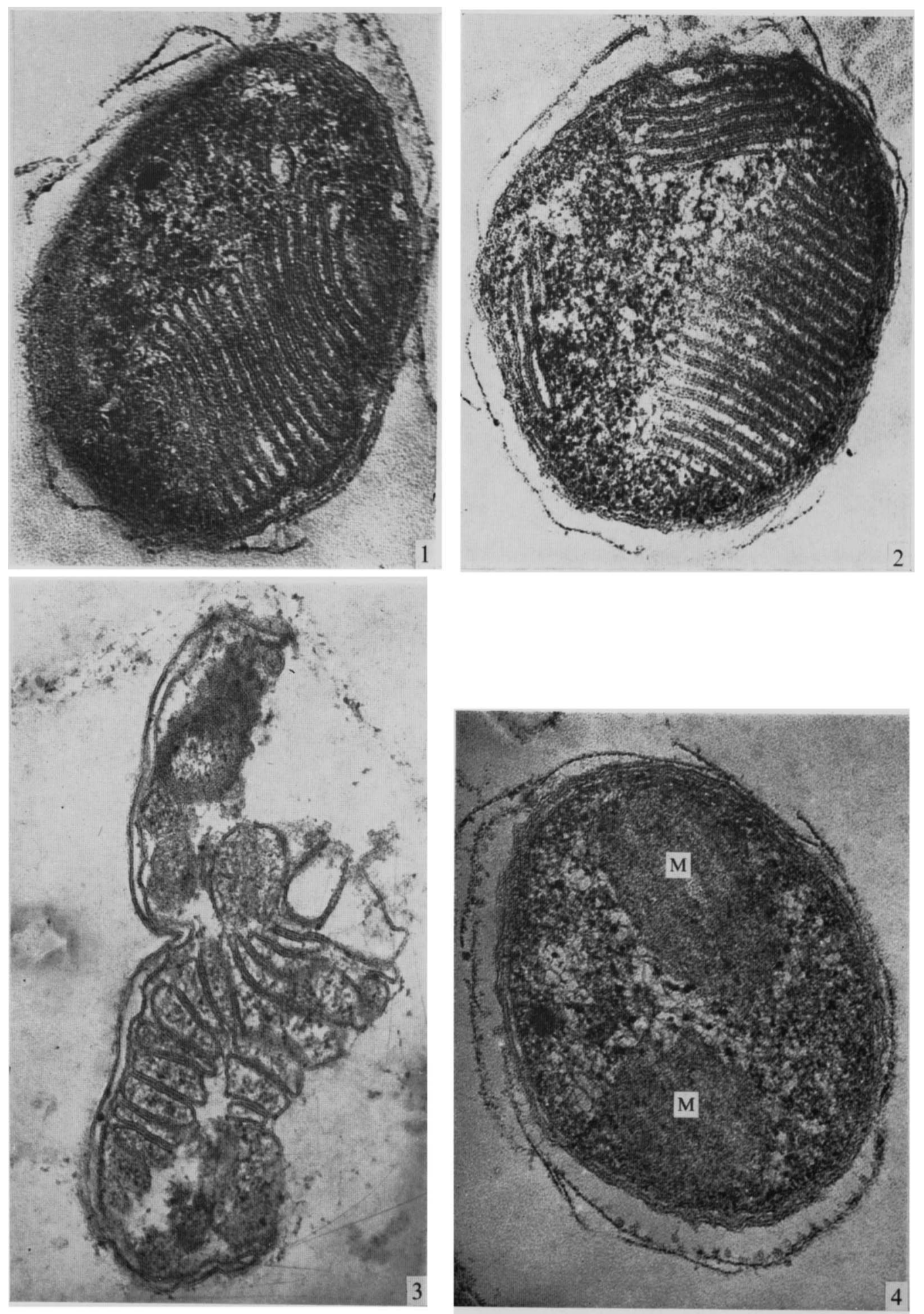
Journal of General Microbiology, Vol. 6I, No. 2

Plate 2
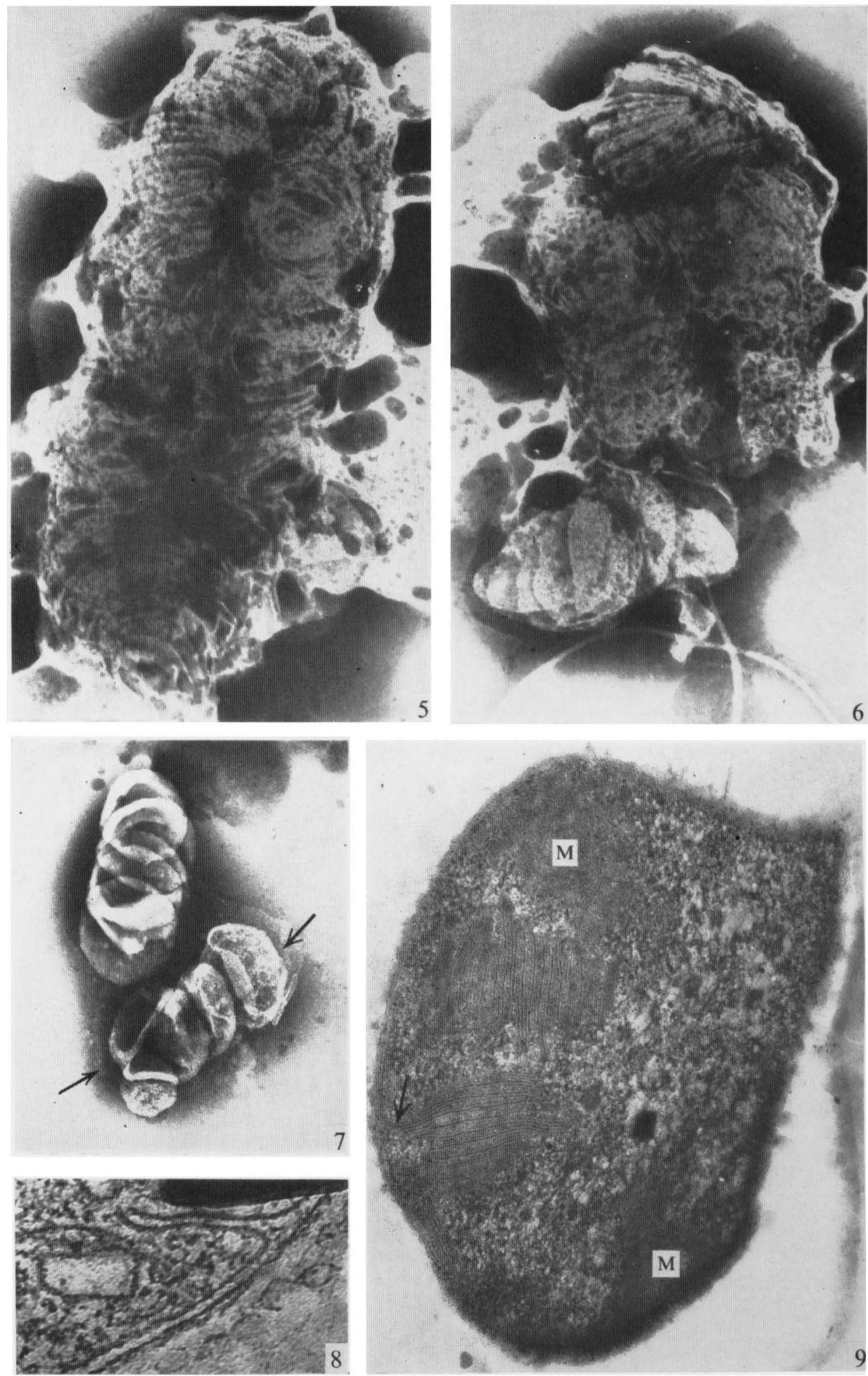

S. L. DAVIES AND R. WHITTENBURY 
Journal of General Microbiology, Vol. 6I, No. 2

Plate 3
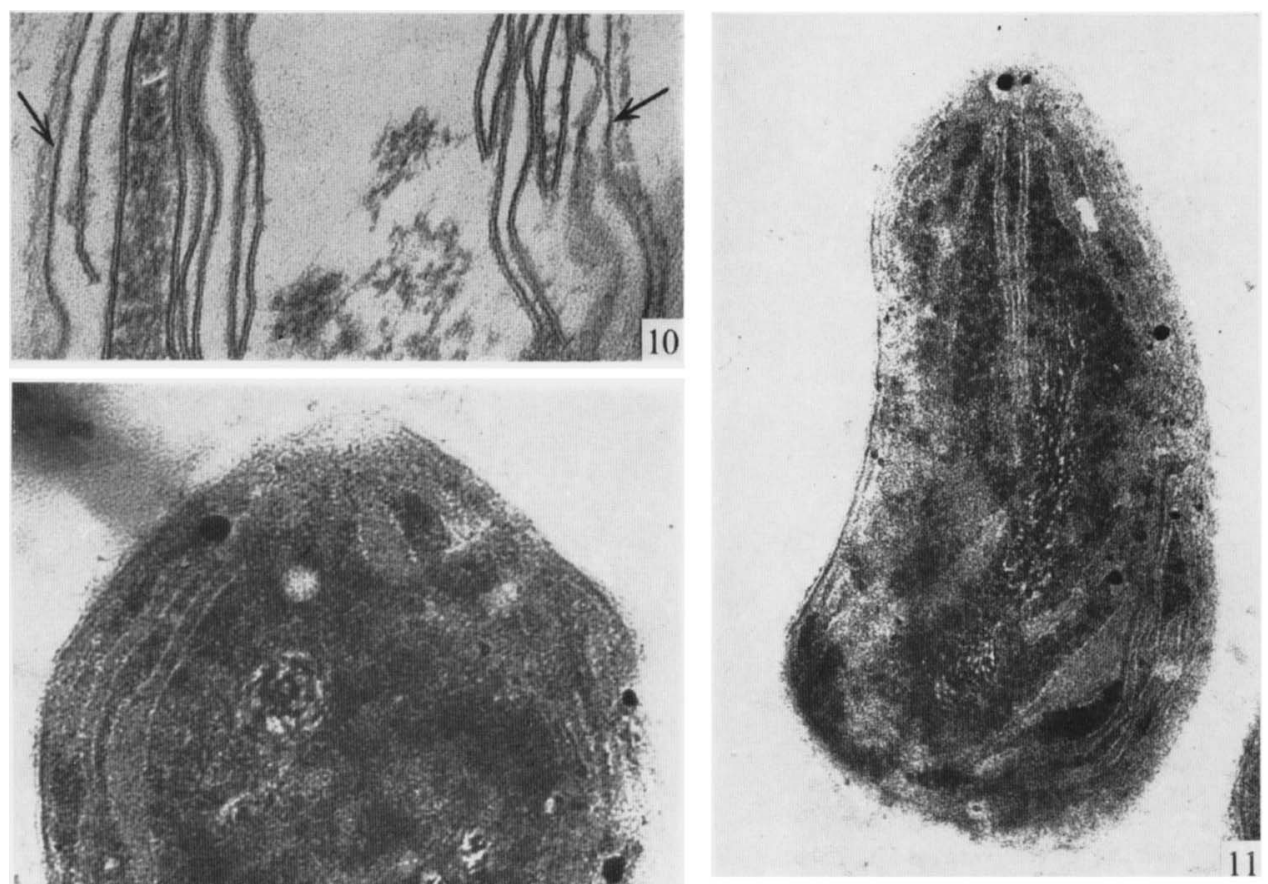

12
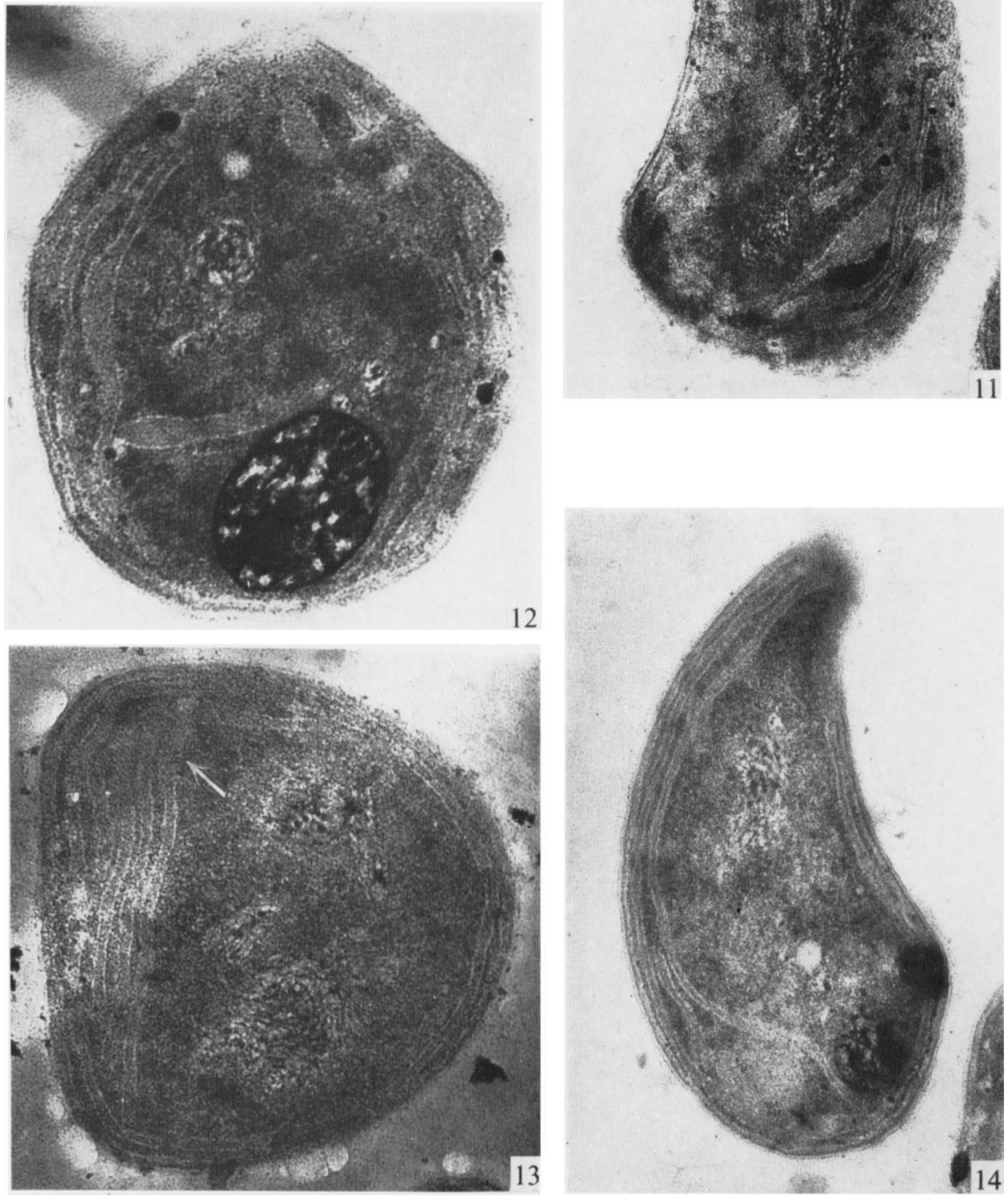

S. L. DAVIES ANII R. WHITTENEURY 
Journal of General Microbiology, Vol. 61, No. 2

Plate 4
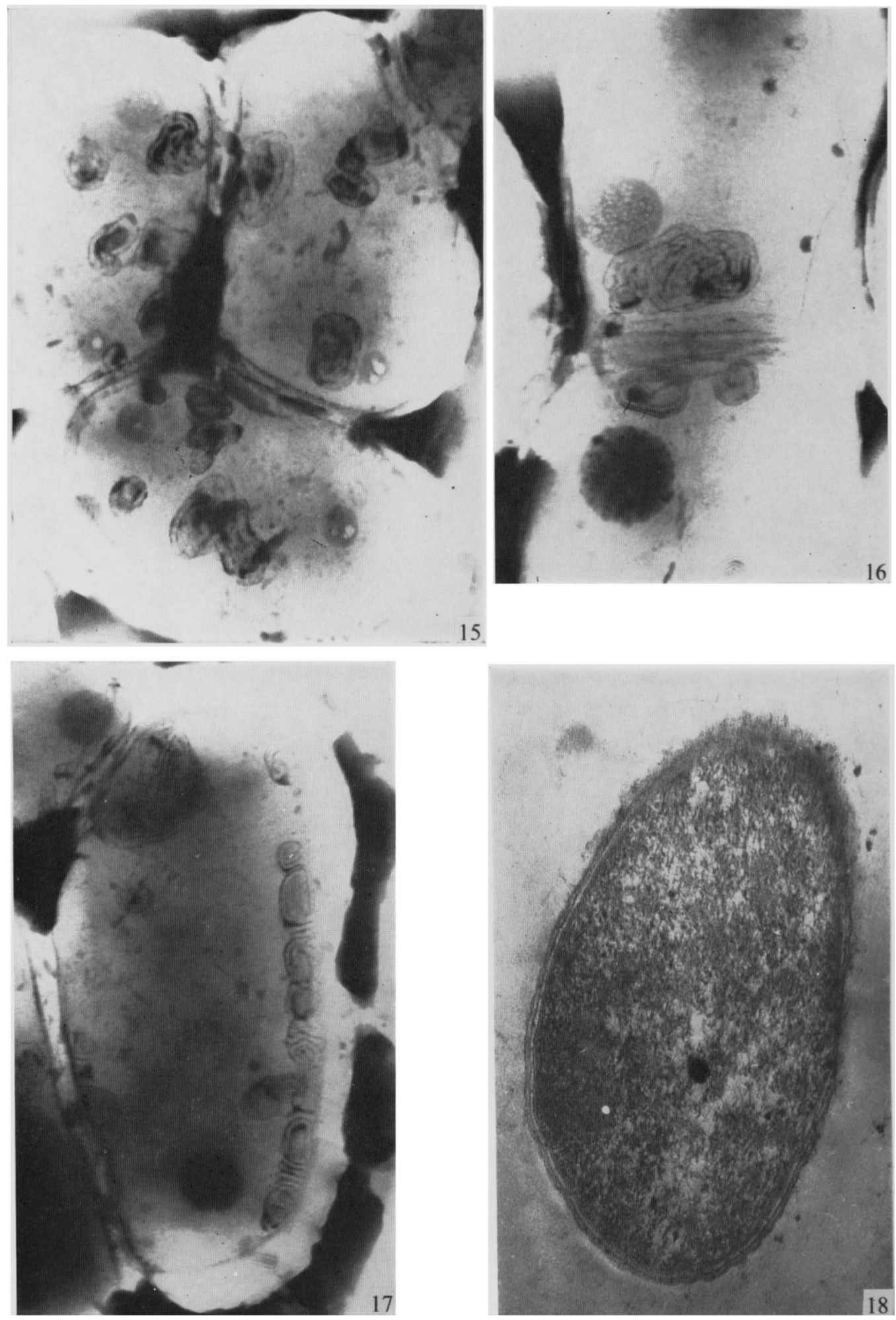

S. L. DAVIES AND R. WHITTENBURY 